Check for updates

Cite this: RSC Adv., 2022, 12, 2736

Received 23rd November 2021 Accepted 26th December 2021

DOI: 10.1039/d1ra08568a

rsc.li/rsc-advances

\section{Copper-assisted preparation of pyridinyl sulfonate esters from hydroxypyridines and sodium sulfinates $\uparrow$}

\author{
Qian Li, ${ }^{a}$ Haibo Zhu, (D) *ab Yishuai Liu, ${ }^{a}$ Liu Yang, ${ }^{a}$ Qiangwen Fan, (D) *ac \\ Zongbo Xie (D) *a and Zhang-Gao Le ${ }^{a}$
}

\begin{abstract}
An efficient and powerful copper-assisted method for the effective conversion of a broad range of hydroxypyridines and sodium sulfinates into their corresponding pyridinyl tosylates was developed. Key features of this base- and ligand-free protocol include using the cheap and readily available $\mathrm{CuBr}_{2} \mathrm{as}$ a medium and the use of sodium sulfinates as formal sulfonylation reagents. A variety of functional pyridinyl tosylates could be formed with good yields, which can easily be converted into $\mathrm{C}-\mathrm{C}$ and $\mathrm{C}-\mathrm{N}$ bond-containing compounds.
\end{abstract}

Sulfonate esters are well-known ester compounds and important pharmaceutical ingredients (Fig. 1) $\cdot{ }^{1-3}$ As a bridge structure or ligand, they have special biological activities in medicinal chemistry, such as undesired thrombosis prevention and monoamine oxidase inhibitory activity. ${ }^{4-6}$ In addition, sulfonate ester groups play a unique role in coupling reactions due to their easy leaving ability. ${ }^{7-11}$ Traditional methods for the synthesis of sulfonate esters have usually focused on the esterification reaction of phenols or alcohols with sulfonyl chlorides, which requires the preparation of unstable and strongly corrosive sulfonyl chlorides in a low temperature system (down to $-20{ }^{\circ} \mathrm{C}$ ). ${ }^{12,13}$ Over the last decade, many chemists have become interested in direct sulfonylation reactions using various sulfonylation reagents, ${ }^{14,15}$ including sulfinic acids, ${ }^{16,17}$ sulfinates ${ }^{18,19}$ and sulfonyl hydrazides. ${ }^{20-22}$

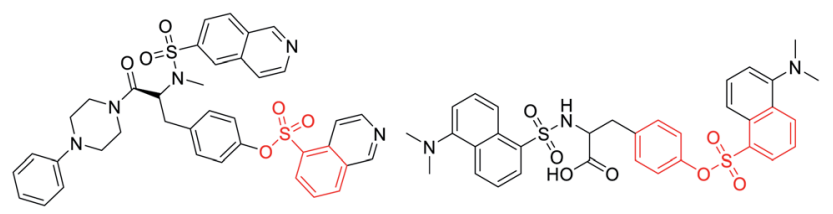

Fig. 1 Representative biologically active sulfonate ester scaffolds.

ajiangxi Province Key Laboratory of Synthetic Chemistry, School of Chemistry, Biology and Material Science, East China University of Technology, 330013, Nanchang, China. E-mail: hbzhu@ecut.edu.cn; fanqw2019@ecut.edu.cn; zbxie@ecut.edu.cn

${ }^{b}$ Jiangxi Province Key Laboratory of Polymer Micro/Nano Manufacturing and Devices, East China University of Technology, Nanchang, 330013, China

Iiangxi Key Laboratory for Mass Spectrometry and Instrumentation, East China University of Technology, Nanchang, 330013, China

$\dagger$ Electronic supplementary information (ESI) available. See DOI: 10.1039/d1ra08568a
Among them, the stable and readily available sodium sulfinate seems to be more attractive because it has demonstrated flexible reactivity, such as being nucleophilic, electrophilic, and a radical reagent by providing suitable reaction conditions. ${ }^{23-26}$ Therefore, it is highly desirable to design and develop a suitable low-cost and green approach to construct sulfonate ester building blocks.

In 2016, Chiranjeevi and co-authors developed an efficient practical tosylation of phenols, employing the mild reagent [DMAPTs $]^{+} \mathrm{Cl}^{-}$under base-free and chromatography-free conditions (Scheme 1a). ${ }^{27}$ Notably, Gao's group reported the synthesis of sulfonate esters induced by iodine through the cross-coupling reaction of sodium sulfinates and phenols (Scheme 1b). ${ }^{28}$ Compared with the reported methods using sulfonyl chlorides as starting materials, the present method

Previous works:

a)

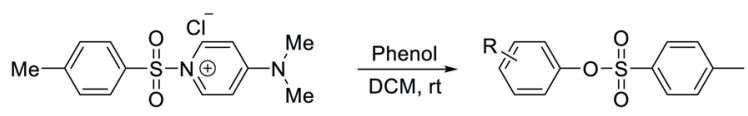

b)

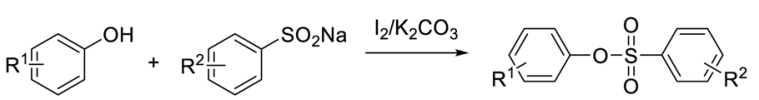

c)

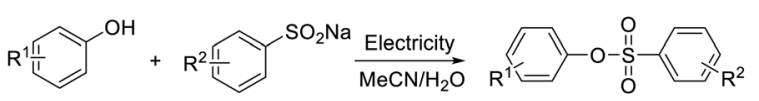

This work:

d)

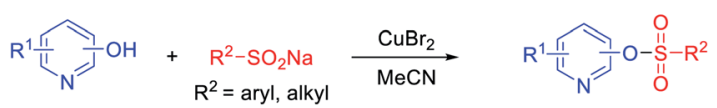

Scheme 1 Methods for the synthesis of (hetero)arylsulfonate esters. 
appears to be more general and efficient for the synthesis of sulfonate esters. Electro-oxidation ${ }^{29,30}$ and transition-metalcatalyzed insertion of sulfur dioxide ${ }^{31-36}$ were also alternatives to generate arylsulfonate esters. An electro-oxidative sulfonylation of phenols with sodium arenesulfinates under mild reaction conditions was developed. This protocol showed a wide substrate scope and high functional group tolerance without external stoichiometric oxidants (Scheme 1c). ${ }^{37}$ Although great progress has been made in the preparation of sulfonate esters, the relevant studies are still in their infancy and a high efficiency protocol for nitrogen-containing heterocycle sulfonate esters is far from fully developed.

On account of our strong interest in researching sulfonylcontaining compounds, ${ }^{\mathbf{1 9}, 38-41}$ herein, we report a facile, costeffective and efficient approach using $\mathrm{CuBr}_{2}$ as a catalytic medium for the cross-coupling reaction of sodium sulfinates and hydroxypyridines to generally prepare a variety of functional pyridinyl sulfonate esters with good yields. The synthetic route has a simple operation and good functional group compatibility, and can afford a series of heterocyclic sulfonate esters with medium to high yields under mild conditions. To the best of our knowledge, such a route for the synthesis of pyridinyl sulfonate esters has not been reported to date.

Our study was initiated by evaluating the model reaction between 2-pyridone $1 \mathrm{a}(0.2 \mathrm{mmol})$ and sodium sulfinate $2 \mathrm{a}(1.0$ equiv.) with $\mathrm{CuBr}_{2}$ as the additive. After a $24 \mathrm{~h}$ reaction at $90{ }^{\circ} \mathrm{C}$ in acetonitrile ( $\mathrm{MeCN})$, the desired product 3a can be isolated in $24 \%$ yield (Table 1, entry 1). Various transition metal catalysts, including copper, nickel, iron salts, and especially palladium catalysts, were then investigated, and $\mathrm{CuBr}_{2}$ was the best additive for this transformation (see ESI for details, Table S1 $\dagger$ ). Further solvent screening indicated that $\mathrm{MeCN}$ is the best solvent; other solvents including polar and non-polar solvents, such as (dimethyl sulfoxide) DMSO, 1,4-dioxane, toluene,

Table 1 Optimization of the reaction conditions ${ }^{a}$

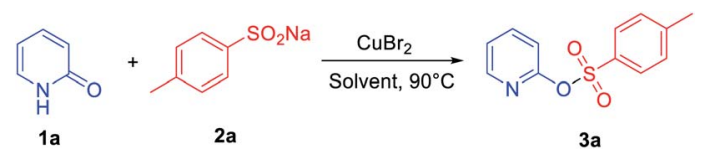

\begin{tabular}{lllll}
\hline Entry & $\mathrm{CuBr}_{2}$ (equiv.) & Solvent & Time (h) & Yield $^{b}(\%)$ \\
\hline 1 & 0.2 & MeCN & 24 & 24 \\
2 & 0.2 & DMSO & 24 & NR \\
3 & 0.2 & Dioxane & 24 & Trace \\
4 & 0.2 & Toluene & 24 & Trace \\
5 & 0.2 & DCE & 24 & 12 \\
6 & 0.2 & DCM & 24 & 12 \\
7 & 0.2 & MeOH & 24 & Trace \\
$8^{c}$ & 0.2 & MeCN & 24 & 36 \\
$9^{c}$ & 0.2 & MeCN & 6 & 42 \\
$10^{c}$ & 0.5 & MeCN & 6 & 48 \\
$\mathbf{1 1}^{c}$ & $\mathbf{1 . 0}$ & MeCN & 6 & 78
\end{tabular}

${ }^{a}$ Reaction conditions: $1 \mathrm{a}(0.2 \mathrm{mmol}), \mathbf{2 a}(1.0$ equiv.) in $2 \mathrm{~mL}$ solvent at $90{ }^{\circ} \mathrm{C}$ under air atmosphere. ${ }^{b}$ Isolated yield. ${ }^{c} 1 \mathrm{a}(0.2 \mathrm{mmol}), 2 \mathrm{a}(1.5$ equiv.).
$\mathrm{MeOH}$, dichloromethane (DCM) and dichloroethane (DCE) gave lower yields (Table 1, entries 2-7). When 1.5 equiv. of 2a was added in this transformation, 36\% isolated yield of 3a was observed (Table 1, entry 8). Interestingly, the product yield was increased to $42 \%$ when the reaction time was shortened to $6 \mathrm{~h}$ (Table 1, entry 9). Besides, raising or lowering the reaction temperature cannot further promote the conversion of the reaction (Table S3, $\dagger$ entries 8 and 9). Generally, nitrogencontaining ligands play a vital role in copper-catalyzed coupling reactions, which could stabilize the active species of the catalyst in the catalytic cycle. However, bipyridine and $o$ phenanthroline ligands were also screened (Table S2, see ESI $\dagger$ for details), and the yield of the desired product 3a was not further improved. Further exploration of cupric dibromide revealed that the reaction worked efficiently in the presence of 1.0 equiv. of copper(II) bromide, producing the corresponding product $3 \mathbf{a}$ in $78 \%$ yield (Table 1 , entry 11). Therefore, the optimized reaction conditions were as follows: $0.2 \mathrm{mmol}$ of $\mathbf{1 a}$ and 1.5 equiv. of $2 \mathrm{a}$ were dissolved in MeCN under air atmosphere at $90{ }^{\circ} \mathrm{C}$ in the presence of $\mathrm{CuBr}_{2}$ ( 1 equiv.).

With the optimized reaction conditions in hand, the copperassisted preparation of pyridinyl sulfonate esters from hydroxypyridines and sodium sulfinates were then explored, and the results are summarized in Tables 2 and 3. Various sodium sulfinates were tolerated; both electron-donating $(-\mathrm{Me},-\mathrm{OMe}$

Table 2 Scope of various sodium sulfonates ${ }^{a}$

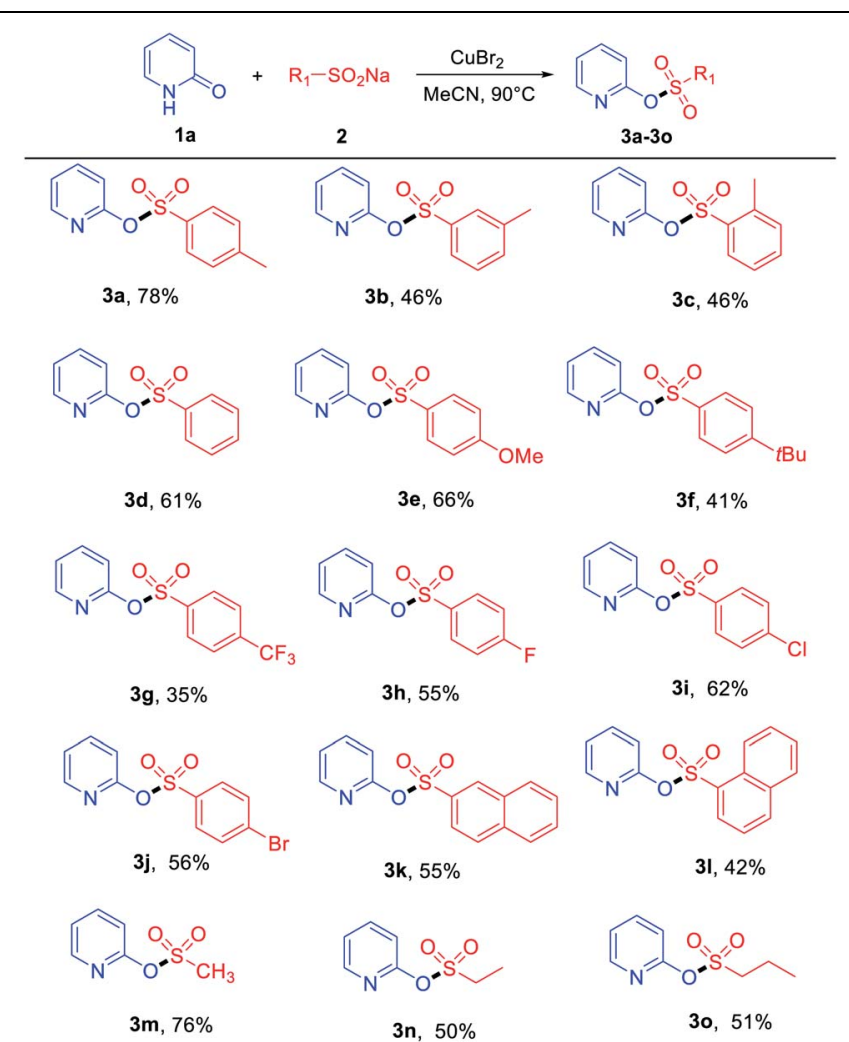

${ }^{a}$ Reaction conditions: $\mathbf{1 a}(0.2 \mathrm{mmol}), \mathbf{2 a}\left(1.5\right.$ equiv.), $\mathrm{CuBr}_{2}$ (1.0 equiv.) in $2 \mathrm{~mL}$ solvent at $90{ }^{\circ} \mathrm{C}$ under air atmosphere. 
Table 3 Synthesis of sulfonate esters with various hydroxypyridines ${ }^{a}$

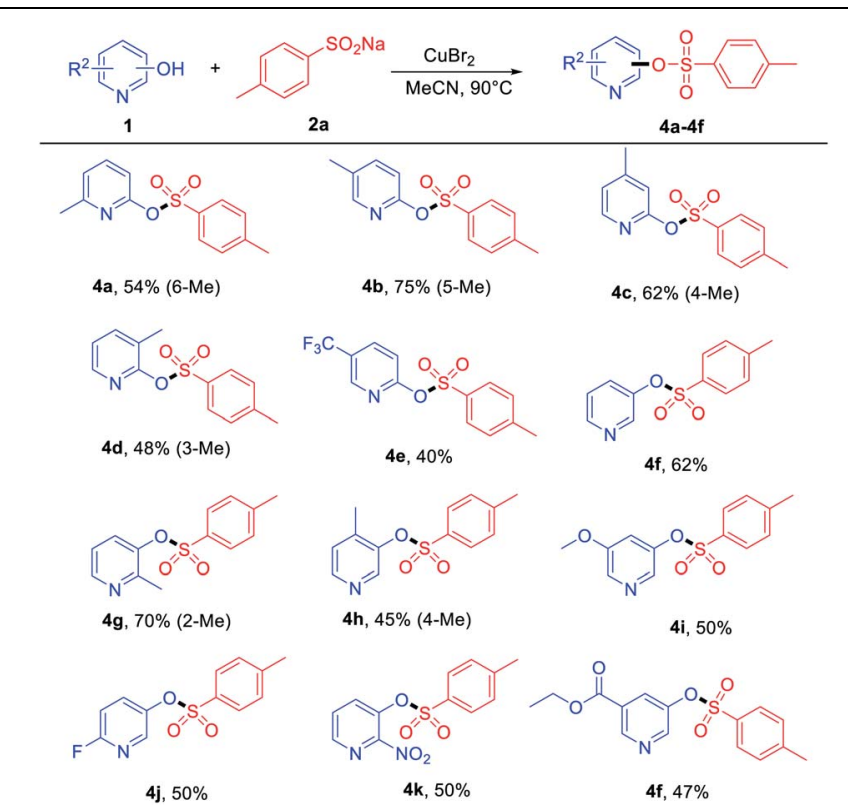

${ }^{a}$ Reaction conditions: $\mathbf{1 a}(0.2 \mathrm{mmol}), \mathbf{2 a}\left(1.5\right.$ equiv.), $\mathrm{CuBr}_{2}$ (1.0 equiv.) in $2 \mathrm{~mL}$ solvent at $90{ }^{\circ} \mathrm{C}$ under air atmosphere.

and $-t \mathrm{Bu})$ and electron-withdrawing groups $\left(-\mathrm{CF}_{3},-\mathrm{F},-\mathrm{Cl}\right.$ and $-\mathrm{Br}$ ) on the phenyl ring afforded the corresponding products in medium to good yields (Table 2). The position of the substituent also affected the reaction. Sodium sulfinates that bear electrondonating groups (as - Me) in the para-position of the phenyl ring were superior to their ortho- and meta-substituted counterparts in isolated yields (Table 2, 3a-3c). Remarkably, sodium naphthalene-2-sulfinate and sodium naphthalene-1-sulfinate also proved to be suitable substrates, providing products $3 \mathbf{k}$ and $\mathbf{3 l}$ in moderate yields. Apart from aromatic sodium sulfinates, less-reactive aliphatic sodium sulfinates, such as sodium methanesulfinate, were tolerated in this transformation, affording products $\mathbf{3 m - 3 o}$ with moderate to good yields.

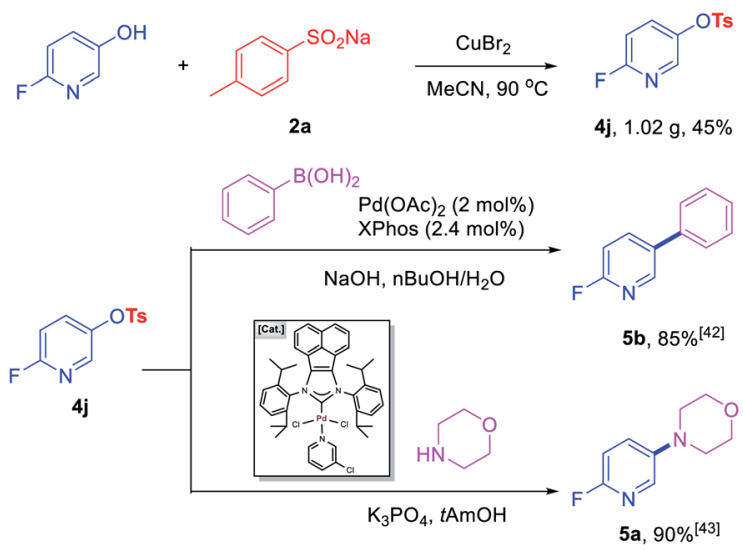

Scheme 2 Gram-scale synthesis and further conversion of $4 \mathrm{j}$.

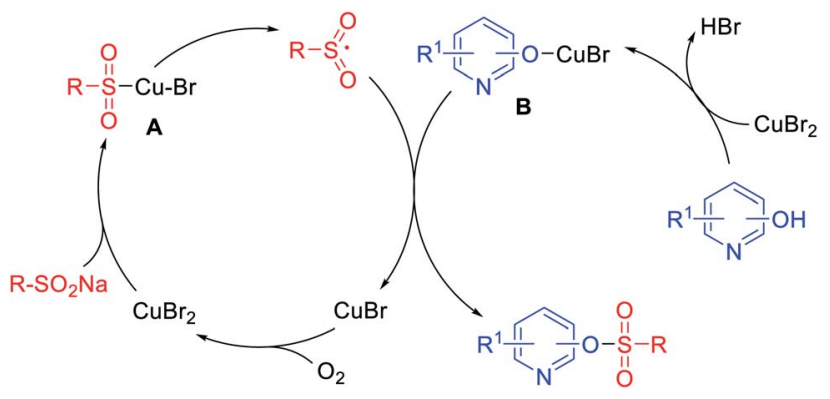

Scheme 3 Possible mechanism.

On the other hand, the reactions of some pyridinols with $\mathbf{2 a}$ and pyridin-3-ol were examined, and the results are summarized in Table 3. A series of ortho- and meta-substituted pyridinols by electron-donating (-Me and -OMe) and electronwithdrawing groups $\left(-\mathrm{F},-\mathrm{CF}_{3}\right.$, and $\left.-\mathrm{NO}_{2}\right)$ all proceeded smoothly to afford the corresponding products (Table 3, 4a-4k) in medium to good yields. When some electron-donating groupsubstituted (as -Me) pyridinols were used, the 4-methyl and 5methyl of the phenyl ring were better than their 3-methyl and 6methyl substituted counterparts in isolated yields (Table 3, 4a4d). This result may be attributed to the fact that the influence of steric hindrance is not conducive to the progress of the reaction. To our delight, the electron-withdrawing group $\left(-\mathrm{NO}_{2}\right)$ performed with good yields (4k). In addition, ethyl 5-(tosyloxy) nicotinate (4f) was also obtained in a medium yield.

To further prove the practicability of this new synthetic method, a gram-scale reaction was performed. A $45 \%$ yield of $4 \mathbf{j}$ $(1.02 \mathrm{~g})$ was formed with $8 \mathrm{mmol}$ 2-fluoro-5-hydroxypyridine and $12 \mathrm{mmol}$ of $\mathbf{2 a}$ under the optimal conditions, which further demonstrate the practical synthetic value of the current methodology (Scheme 2a). In addition, further transformations of $4 \mathbf{j}$ were performed to demonstrate the potential application of the products in the construction of $\mathrm{C}-\mathrm{C}$ and $\mathrm{C}-\mathrm{N}$ bonds. Room-temperature Suzuki-Miyaura coupling of heteroaryl tosylates $\mathbf{4 j}$ with phenylboronic acid could afford $\mathbf{5 b}$ with $85 \%$ yield (Scheme 2b). ${ }^{\mathbf{4 2}}$ Amination of $\mathbf{4 j}$ furnished heterocyclic amine $5 \mathbf{a}$ in $90 \%$ yield in the presence of robust acenaphthoimidazolylidene palladium complex (Scheme 2c). ${ }^{\mathbf{4 3}}$

To investigate the possible reaction mechanism, radical trapping experiments were performed. No sulfonate ester product was detected in the presence of the radical scavengers TEMPO or BHT, which indicated that a radical pathway should be involved. ${ }^{\mathbf{4 4 , 4 5}}$ According to the above results, a possible mechanism is proposed in Scheme 3. Initially, a sulfonyl intermediate $\mathbf{A}$ is generated by the coordination of copper to the sodium sulfinate, ${ }^{\mathbf{4 6 , 4 7}}$ which decompose into the sulfonyl free radical intermediate and $\mathrm{CuBr}$. The coordination of hydroxypyridine with copper occurs to generate intermediate $\mathbf{B}$, which combines with the sulfonyl free radical to give the sulfonate ester with release of $\mathrm{CuBr}$. Finally, $\mathrm{CuBr}$ can be oxidized by $\mathrm{O}_{2}$ to generate $\mathrm{Cu}(\mathrm{II})$ species. $^{48}$ 


\section{Conclusions}

In conclusion, $\mathrm{CuBr}_{2}$ has been demonstrated as a highly efficient promoter in the direct hydroxylsulfonylation of readily available pyridinols with functional (hetero)aryl- or alkylsodium sulfinates. Remarkably, this protocol presented a direct, mild and efficient approach with good functional group tolerance to access diverse pyridinyl sulfonate esters. Further study on this reaction's application is currently ongoing in our laboratory.

\section{Conflicts of interest}

The authors have no conflicts of interest to declare.

\section{Acknowledgements}

Financial support from the National Natural Science Foundation of China (No. 21801040, 22102022), the Natural Science Foundation of Jiangxi Province (20192BAB213006, 20181BBH80007), the Opening Project of Jiangxi Province Key Laboratory of Polymer Micro/Nano Manufacturing and Devices (PMND202001), the Open fund of Jiangxi Key Laboratory for Mass Spectrometry and Instrumentation (No. JXMS202106), East China University of Technology Research Foundation for Advanced Talents (No. DHBK2017168) and School of Chemistry, Biology and Material Science at East China University of Technology is gratefully acknowledged.

\section{Notes and references}

1 L. M. Betts, N. C. Tam, S. M. H. Kabir, R. F. Langler and I. Crandall, Aust. J. Chem., 2006, 59, 277-282.

2 S. Fortin, L. Wei, E. Moreau, J. Lacroix, M. F. Cote, E. Petitclerc, L. P. Kotra and R. C.-Gaudreault, J. Med. Chem., 2011, 54, 4559-4580.

3 N. Jalalian, T. B. Petersen and B. Olofsson, Chem, 2012, 18, 14140-14149.

4 J. H. Park, G. E. Lee, S. D. Lee, T. T. Hien, S. Kim, J. W. Yang, J. H. Cho, H. Ko, S. C. Lim, Y. G. Kim, K. W. Kang and Y. C. Kim, J. Med. Chem., 2015, 58, 2114-2134.

5 D. Tondi, A. Venturelli, S. Ferrari, S. Ghelli and M. P. Costi, J. Med. Chem., 2005, 48, 913-916.

6 H.-B. Zhou, J. S. Comninos, F. Stossi, B. S. Katzenellenbogen and J. A. Katzenellenbogen, J. Med. Chem., 2005, 48, 72617274.

7 C.-H. Cho, H.-S. Yun and K. Park, J. Org. Chem., 2003, 68, 3017-3025.

8 Y.-Y. Gui, L.-L. Liao, L. Sun, Z. Zhang, J.-H. Ye, G. Shen, Z.-P. Lu, W.-J. Zhou and D.-G. Yu, Chem. Commun., 2017, 53, 1192-1195.

9 Y. Zhang, G. Lavigne and V. César, J. Org. Chem., 2015, 80, 7666-7673.

10 T. Ogata and J. F. Hartwig, J. Am. Chem. Soc., 2008, 130, 13848-13849.

11 H. N. Nguyen, X. Huang and S. L. Buchwald, J. Am. Chem. Soc., 2003, 125, 11818-11819.
12 G. Song, Y. Cai and Y. Peng, J. Comb. Chem., 2005, 7, 561566.

13 L. J. Gooßen, N. Rodríguez, P. P. Lange and C. Linder, Angew. Chem., Int. Ed., 2010, 49, 1111-1114.

14 D. Joseph, M. A. Idris, J. Chen and S. Lee, ACS Catal., 2021, 11, 4169-4204.

15 V. K. K. Pampana, V. P. Charpe, A. Sagadevan, D. K. Das, C.-C. Lin, J. R. Hwu and K. C. Hwang, Green Chem., 2021, 23, 3569-3574.

16 J. Wen, W. Shi, F. Zhang, D. Liu, S. Tang, H. Wang, X.-M. Lin and A. Lei, Org. Lett., 2017, 19, 3131-3134.

17 G. Zhang, L. Zhang, H. Yi, Y. Luo, X. Qi, C.-H. Tung, L.-Z. Wu and A. Lei, Chem. Commun., 2016, 52, 10407-10410.

18 Y. Liu, H. Zhu, L. Yang, Z. Xie, G. Jiang, Z.-G. Le and T. Tu, Asian J. Org. Chem., 2020, 9, 247-250.

19 H. Zhu, Y. Shen, Q. Deng and T. Tu, Chem. Commun., 2015, 51, 16573-16576.

20 G. Zhang, L. Zhang, H. Yi, Y. Luo, X. Qi, C.-H. Tung, L.-Z. Wu and A. Lei, Chem. Commun., 2016, 52, 10407-10410.

21 H. Zhu, Y. Zhang, Y. Liu, L. Yang, Z. Xie, G. Jiang and Z.-G. Le, Tetrahedron Lett., 2020, 61, 151975.

22 B. Gong, H. Zhu, Y. Liu, Q. Li, L. Yang, G. Wu, Q. Fan, Z. Xie and Z. Le, Green Synth. Catal., 2021, DOI: 10.1016/ j.gresc.2021.10.002.

23 W. Dong, Z.-Y. Fang, T.-Y. Cao, J.-H. Cao, Z.-Q. Zhao, L. Zhang, W. Li, L. Qi and L.-J. Wang, Org. Lett., 2021, 23, 5809-5814.

24 Z. Guo, Y. Zhao, Y. Wang, M. Xie and J. Zhang, J. Org. Chem., 2021, 86, 6247-6258.

25 Y. Wu, J. Chen, L. Li, K. Wen, X. Yao, J. Pang, T. Wu and X. Tang, Org. Lett., 2020, 22, 7164-7168.

26 Y.-S. Xiong, B. Zhang, Y. Yu, J. Weng and G. Lu, J. Org. Chem., 2019, 84, 13465-13472.

27 C. Dhonthulachitty, S. R. Kothakapu and C. K. Neella, Tetrahedron Lett., 2016, 57, 4620-4623.

28 J. Gao, X. Pan, J. Liu, J. Lai, L. Chang and G. Yuan, RSC Adv., 2015, 5, 27439-27442.

29 H. Wang, X. Gao, Z. Lv, T. Abdelilah and A. Lei, Chem. Rev., 2019, 119, 6769-6787.

30 Y. Yuan and A. Lei, Acc. Chem. Res., 2019, 52, 3309-3324.

31 Y. Wang, L. Deng, Y. Deng and J. Han, J. Org. Chem., 2018, 83, 4674-4680.

32 A. L. Tribby, I. Rodríguez, S. Shariffudin and N. D. Ball, J. Org. Chem., 2017, 82, 2294-2299.

33 T. S.-B. Lou, S. W. Bagley and M. C. Willis, Angew. Chem., Int. Ed., 2019, 58, 18859-18863.

34 M. Wang and X. Jiang, Chem. Rec., 2021, 21, 1-19.

35 H. Zhang, M. Wang and X. Jiang, Green Chem., 2020, 22, 8238-8242.

36 D. Zeng, M. Wang, W.-P. Deng and X. Jiang, Org. Chem. Front., 2020, 7, 3956-3966.

37 Z. Tian, Q. Gong, T. Huang, L. Liu and T. Chen, J. Org. Chem., 2021, 86, 15914-15926.

38 H. Zhu, Y. Liu, Y. Zhang, L. Yang, J. Meng, Q. Li, B. Gong, Z. Xie and Z.-G. Le, Mol. Catal., 2021, 505, 111500.

39 H. Zhu, Y. Shen, Q. Deng, J. Chen and T. Tu, ACS Catal., 2017, 7, 4655-4659. 
40 H. Zhu, Y. Shen, Q. Deng, J. Chen and T. Tu, Chem. Commun., 2017, 53, 12473-12476.

41 H. Zhu, Y. Shen, D. Wen, Z.-G. Le and T. Tu, Org. Lett., 2019, 21, 974-979.

42 J. Yang, S. Liu, J.-F. Zheng and J. Zhou, Eur. J. Org. Chem., 2012, 2012, 6248-6259.

43 T. Tu, Z. Sun, W. Fang, M. Xu and Y. Zhou, Org. Lett., 2012, 14, 4250-4253.
44 G. O. Jones, P. Liu, K. N. Houk and S. L. Buchwald, J. Am. Chem. Soc., 2010, 132, 6205-6213.

45 C. Tang and N. Jiao, J. Am. Chem. Soc., 2012, 134, 18924.

46 X. Tang, L. Huang, C. Qi, X. Wu, W. Wu and H. Jiang, Chem. Commun., 2013, 49, 6102-6104.

47 X. Yu, X. Li and B. Wan, Org. Biomol. Chem., 2012, 10, 74797482.

48 J. Chen, Y. Sun, B. Liu, D. Liu and J. Cheng, Chem. Commun., 2012, 48, 449-451. 